\title{
LA EMPRESA AGRARIA MONÁSTICA EN ANDALUCÍA. GESTIÓN DE LAS EXPLOTACIONES AGRARIAS DE LA ORDEN CARTUJA (SIGLOS Xv-XIX) '
}

por

\section{ANTONIO LUIS LÓPEZ MARTÍNEZ}

Facultad de Ciencias Econónicas y Empresariales Universidad de Sevilla

RESUMEN: $A$ lo largo de los siglos la administración de los dominios conventuales ha tratado de adecuarse a los cambios habidos en la coyuntura economica. Estas transformaciones en la gestion tuvieron como principal objetivo un incremento de los beneficios. Con el análisis de las explotaciones practicadas por los cartujos andaluces tratamos de mostrar como los principales cambios habidos en la gestión de su patrimonio, reducción de los plazos de arrendamiento, sustitución de la renta en especie por renta en metalico, introducción de cultivos de mayor rentabilidad económica y, por último, la explotación directa, que permiten diversificar las fuentes de ingresos, se produjo un notable incremento de los beneficios monásticos.

Palabras clave. Agrtcultura, Andalucia, Antiguo Régimen, Cartujos, Economías Monasticas.

ABSTRACT: Along the centuries the management of the conventual domains have treated to the changes of the economical conjunctu re. These transformations in the negotiation had like main objetive an increase of the profits. With the analysis of the exploitations practised by the andalusians carthusians we treat to show how the main changes have been in the management from patrimony, reduction of the rental's durations, subtitutions of the rents in

\footnotetext{
I Los archivos consultados en este artículo son los siguientes:

- Archivo Arzobispal de Sevilla (AAS)

- Archivo de la Catedral de Sevilla (ACS)

- Archivo Histórico Nacional (AHN)

- Archivo Histórico Provincial de Cádiz (AHPC)

- Archivo Histórico Provincial de Sevilla (AHPSE)

- Archivo de la Provincia Bética Franciscana (APBF)

En lo sucesivo se citarán por las sigias correspondientes.
} 
species for rents in money, introductions of cultivations of more economical rentability and, for last, the direct exploitation, that allow to diversify the sources of eamings, it produced a notable increase of the monastic incomes.

KEY WORDS: Agriculture, Andalucía, Early Modern Times, Carthusians, Monastic economics

El recurso a los tópicos cuando se habla de «bienes eclesiásticos» es algo bien corriente, incluso, cuando dicho tema es tratado por algunos historiadores. El primero de los tópicos al uso es el de la generalización, se habla de bienes eclesiásticos como si en todos los casos se tratase de la misma cosa, sin tener en cuenta las diferencias existentes entre las distintas instituciones eclesiásticas propietarias. El segundo tópico es la de considerar como despilfarro social la "descuidada y rutinaria" gestión que las citadas instituciones han llevado a cabo en sus propiedades, ya sea por su incapacidad a la hora de buscar el beneficio, ya sea por desidia, dado que por su abundancia de ingresos no tenían el menor interés en incrementarlos ${ }^{2}$. De todo lo cual surge la figura tópica del religioso despreocupado por los asuntos de este mundo que deja la gestión del patrimonio eclesiástico en manos de administradores que sólo buscan su propio provecho ${ }^{3}$.

También se pueden considerar como tópicos ciertos enfoques del tema cargados de prejuicios ideológicos. Aquí incluiríamos aquellos historiadores que de entrada colocan a la administración de las propiedades eclesiásticas la etiqueta de «sistema de explotación feudal», basándose únicamente en que se trata de propiedades amortizadas. Esto da a sus interpretaciones un marcado sesgo unilateral, ignorando que algunas de estas administraciones presentan rasgos a los que no cabe de ningún modo la etiqueta de feudal ${ }^{4}$. Tampoco, en buena parte de las propiedades eclesiásticas se produce división de dominio, con la separación entre dominio eminente y dominio útil, otra de las características del sistema feudal, en concreto en las andaluzas donde la propiedad de las instituciones eclesiásticas sobre sus dominios es plena sin ningún tipo de discusión ni limitación.

A nuestro modo de ver todos estos tópicos parten del desconocimiento de los archivos conventuales, ricos en contabilidades de las explotaciones

\footnotetext{
${ }^{2}$ Los ilustrados napolitanos se quejaban de que la gran masa de bienes inmuebles eclesiásticos constituian un obstáculo que impedía una mejora sensible de las condiciones de vida de la población meridional italiana en su conjunto, Dandolo. F. C., La propietà monastica in Puglia nella prima metà dell'Ottocento, Napoli, 1994, pág. 17.

3 Algunos autores, uno de los últimos Tortella, Gabriel, El desarrollo de la España Contenporánea. Historia económica de los siglos XIX y XX, Madrid, 1994, págs. 51-52, plantean la hipótesis de que tras la desamortización eclesiástica tuvo que haberse producido un aumento de la producción agrícola como consecuencia de la puesta en cultivo de tierras de propiedad eclesiástica no cultivadas y de una mejora de los cultivos de las descuidadas tierras de la lglesia.

4 AtIenza, Angela, Propiedad y señorio en Aragón. El clero regular ante la expansión y la crisis /1700-1835), Zaragoza, 1993, pág. 98, hace especial hincapie en el carácter feudal de las propiedades del clero, subordinando casi todo su análisis de la economía de los conventos aragoneses a esta consideración, aún reconociendo que en las relaciones de los conventos con los colonos que llevan en arrendamiento sus propieđades no media ningún tipo de coacción ni de exacción extraeconómica.
}

Hispania, LVI1/2, núm. 196 (1997) 709-729 
monásticas, así como de los autores de la época, que criticaron de manera machacona la gestión directa de los frailes. Las variedades que se observan en la administración llevada a cabo por las distintas instituciones eclesiásticas fueron notables. Incluso, dentro de una misma orden existen marcadas disparidades entre diferentes conventos. En primer lugar en función del sexo de los religiosos, existen importantes diferencias entre las haciendas de los conventos masculinos y femeninos. En segundo lugar, las desigualdades son debidas a la naturaleza de la orden y, sobre todo, a la antigüedad de sus reglas ${ }^{5}$. Por último las diferencias obedecen a la zona donde está enclavado el convento, que no sólo determinan patrimonios de naturaleza muy distinta sino tambien muy desiguales procedimientos de gestión ${ }^{6}$.

Lo que pretendemos demostrar en este artículo es, primero, que determinados institutos regulares llevaron a cabo una administración muy cuidadosa de sus bienes, que en modo alguno puede considerarse menos provechosa ni económica ni socialmente que la practicada por otros propietarios laicos. Segundo, que dicha gestión no permaneció inalterable a lo largo del tiempo, ajena a los cambios de la coyuntura, sino que, por el contrario, trató de adecuarse, en ocasiones con más prontitud que otras, a las cambiantes circunstancias. Por último, se observa que en varias órdenes regulares las transformaciones que tuvieron lugar en la gestión de sus haciendas estuvieron presididas por el objetivo de optimizar sus beneficios gracias a la adopción de opciones que manifiestan una clara racionalidad económica.

Estas hipótesis nuestras ya habían sido planteadas con anterioridad, como veremos, por los autores ilustrados que criticaban la explotación directa de sus propiedades por los regulares y que consiguieron del monarca la prohibjción de que comercializasen ellos mismos su excedente, por considerarlo indigno de su condición. En nuestra época algunos historiadores han destacado la importante renovación experimentada por las economías monásticas como respuesta a la crisis del siglo XVII ${ }^{7}$. También en otros paises de nuestro

5 A este respecto observense las transformaciones que tienen lugar en el dominio del monasterio portugués del Pedroso, que había pertenecido a la orden benedictina y que posteriomente fue adjudicado a los jesuitas para atender los gastos de su colegio de Coimbra. Mientras los primeros habían practicađo una gestión eminentemente rentista, los jesuitas van a primar la gestión directa, Mostejro, I. B. da C., A administraçao jesuita do mosteiro de Pedroso de 1560 aos finais do séc. $x V I$, Porto, 1993, pág. 193-224.

6 Los jesuitas de Cádiz tienen como principal fuente de ingresos la renta de sus numerosas casas en la ciudad, invirtiendo parte de sus beneficios en adquirir nuevos edificios. Sin embargo, en los dos cortijos que tenian en Utrera, donación del fundador del colegio, el comerciante F. Arguijo, nunca se llevó a cabo una explotación directa de sus tierras, a diferencia de lo que hicieron otros colegios, por ejemplo el de Jerez en las suyas.

7 López Garcla, J. M., La transición del feudalismo al capitalismo en un señorio monástico castellano. El abadengo de la Santa Espina (1147-1835), Valladolid, 1990, págs. 460-461 ha contrapuesto las respuestas ofrecidas ante la crisis de la economía castellana por la nobleza laica y las comunidades de regulares. Mientras los primeros buscaron el apoyo de la monarquía bajo la fórmula de nuevas concesiones y prebendas, los regulares pusieron en marcha una serje de medidas todas ellas encaminadas a intensificar y diversificar sus explotaciones directas. 
ámbito geográfico ${ }^{8}$ y cultural ${ }^{9}$ se ha destacado este tipo de evolución en la administración de las haciendas monásticas.

Para tratar de demostrar la racionalidad económica de las opciones adoptadas por las economías monásticas andaluzas en la Edad Moderna hemos escogido a dos de las más importantes comunidades andaluzas, las cartujas de Sevilla y Jerez de la Frontera, ambas fundadas en el siglo xv y que llegaron a contar con un importante patrimonio, según sus respuestas al Catastro de Ensenada (cuadro 1).

CUADRO I

APROVECHAMIENTOS DE LAS PROPIEDADES RÚSTICAS DE LAS CARTUYAS DE SEVILLA Y YEREZ DE LA FRONTERA, SEGÚN EL CATASTRO DE ENSENADA

\begin{tabular}{lrr} 
& Sevilla & Jerez \\
\hline Cereal & 2.924 & 5.563 \\
\hline Olivar & 455 & 1.388 \\
\hline Viña & 10 & 108 \\
\hline Huerta & 36 & s.e \\
\hline Pinar & 273 & 64 \\
\hline Pastos & 2.483 & 589 \\
\hline Total & 6.181 & 7.712 \\
\hline
\end{tabular}

superticie en aranzadas

Fuente: ACS, Mesa Capitular, 1.174.(94).

Son cuatro las principales transformaciones llevadas a cabo por los cartujos en la gestión de sus propiedades:

- Adquisición de nuevas propiedades rústicas y concentración de las ya existentes con el fin de conseguir una gestión más eficaz de su patrimonio ${ }^{10}$

- Cambios en los sistemas de arrendamiento de sus propiedades: reducción de los plazos de arrendamiento y sustitución de la renta en especie por renta en metálico.

8 En el caso de Portugal MAIA, F. P. Sousa, O mosteiro de Bustelo: propiedade e produçâo agrícola no Antigo Regime (1638-1670 e 1710-182I), Porto, 1991, págs. 238-239 afirma que los monjes del monasterio de Bustelo se comportaron, más como auténticos empresarios capitalistas, que como simples rentistas, destacando entre sus actividades la estrategia seguida en la compra de sus propiedades, el cerramiento de las propiedades de explotación directa y la sustitución del trigo, de baja rentabilidad por otros cultivos como viñedo, frutales y olivos.

9 Hay que destacar de manera especial el carácter innovador de las explotaciones agrarias de Ios jesuitas en América, ver TOVAR PINZÓN, Hector: «Elementos constitutivos de la empresa agraria jesuita en la segunda mitad del siglo xvilı en Máxicon en FLoRES CANo (dir.): Haciendas, latifundios y plantaciones en América Latina, México, 1978.

10 En publicaciones anteriores hemos estudiado los criterios seguidos por las órdenes monásticas andaluzas en la adquisición de sus propiedades, vid. LópEz MARTfNEZ, A. L., La economía de las órdenes religiosas en el Antiguo Régimen. Sus propiedades y rentas en el Reino de Sevilla, Sevilla, págs. 164-184.

Hispania, LV11/2, núm. 196 (1997) 709.729 
- Introducción o intensificación de nuevos aprovechamientos, olivar y ganadería ".

- Explotación directa de sus propiedades rústicas, especialmente cereales.

\section{EXPLOTACIÓN dE LAS PROPIEDADES RÚSTICAS DE LA ORDEN CARTUJA EN ANDALUCIA}

Tres fueron los sistemas que utilizaron las cartujas andaluzas en la explotación de sus propiedades rústicas: arrendamiento temporal, explotación directa y cesión a tributo perpetuo. La distribución de la superficie explotada (cuadro 3) según los diferentes sistemas no permaneció invariable sino que evolucionó a lo largo del tiempo de acuerdo con criterios, como veremos, siempre encaminados a incrementar los ingresos de la comunidad.

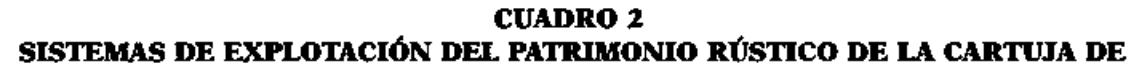 JEREZ DE LA FRONTERA (1578-1835)}

\begin{tabular}{cccccccc} 
Años & 1 & $\%$ & 2 & $\%$ & 3 & $\%$ & Total \\
\hline 1578 & 3.424 & 44,6 & 2.340 & 30,5 & 1.918 & 24,9 & 7.682 \\
\hline 1620 & 2.288 & 31,2 & 1.945 & 26,5 & 3.098 & 42,3 & 7.331 \\
\hline 1651 & 2.269 & 27,6 & 3.430 & 41,7 & 2.518 & 30,7 & 8.217 \\
\hline 1668 & 3.029 & 41,1 & 3.430 & 46,5 & 918 & 12,4 & 7.377 \\
\hline 1677 & 3.289 & 44,7 & 3.430 & 46,6 & 637 & 8,7 & 7.356 \\
\hline 1689 & 2.523 & 40,0 & 3.430 & 54,3 & 362 & 5,7 & 6.315 \\
\hline 1717 & 2.336 & 31,8 & 4.734 & 64,4 & 275 & 3,8 & 7.365 \\
\hline 1750 & 2.074 & 26,3 & 5.597 & 71,1 & 200 & 2,6 & 7.871 \\
\hline 1810 & 1.790 & 19,9 & 7.020 & 77,9 & 197 & 2,2 & 9.007 \\
\hline 1820 & 7.650 & 81,0 & 1.603 & 17,0 & 197 & 2,0 & 9.450 \\
\hline 1835 & 9.220 & 96,7 & 115 & 1,2 & 197 & 2,1 & 9.532 \\
\hline
\end{tabular}

superficie: aranzadas

claves: $1=$ arrendamiento temporal; $2=$ explotación directa; $3=$ cesión a tributo perpetuo

Fuente: 1578 (APBF, códice 219), 1620 (AHPC, libro 11), 1651 (APBF, códice 221), 1668 (APBF, leg. 1), 1677 (APBF, cód. 220), 1689 (AHN, clero, lib. 1.918), 1717 (ACS, Mesa Capitular, 1.165b), 1752 (ACS, Mesa Capitular, 1.174.(94), 1810 (APBF, carpeta Ba), 1820 (APBF, cod. 178), 1835 (APBF, leg.1)

Del cuadro 2 se desprende que el arrendamiento temporal fue predominante $(44,6 \%)$ durante el siglo $\mathrm{xvI}$; la cesión de tierras a tributo perpetuo fue la modalidad más utilizada por los cartujos $(42,3 \%)$ durante la primera mitad

11 Para la ganadería monástica vid. LÓPEZ MARTINEZ, A. L, La economía de las órdenes religiosas..., págs. 309-314. En el caso concreto de la ganadería de la cartuja de Jérez preparamos un estudio más detallado. 
del siglo xvח ${ }^{12}$ y, por último, la explotación directa se impuso desde mediados del siglo XVII hasta comienzos del siglo XIX, llegando a explotar mediante este sistema más de las $3 / 4$ partes de sus propiedades.

\section{Los contratos de arrendamiento temporal}

En la explotación de los latifundios andaluces predominó hasta mediados del siglo XIX el sistema de arrendamiento temporal ${ }^{13}$. Era muy raro que los grandes propietarios cultivasen directamente sus propiedades, excepción hecha de los olivares ${ }^{14}$. El contrato de arrendamiento temporal es un instrumento de carácter legal que se fue configurando desde fines de la Edad Media hasta el siglo XVIII ${ }^{15}$. Se trata de un contrato libre que vincula a propietario y arrendatario, destacando claramente el derecho a la propiedad como principal y absoluto. El colono es usufructuario del predio agrícola durante el tiempo del contrato, pero careciendo de cualquier derecho, incluso el de tanteo, al finalizar el contrato ${ }^{16}$.

Algunas cláusulas de los contratos de arrendamiento temporal fueron evolucionando a lo largo del tiempo, con el objeto de maximizar la renta de la tierra. Dichos cambios fueron, especialmente, destacados, en el Valle del Guadalquivir, donde la agricultura era especialmente sensible al mercado, sufriendo la renta importantes transformaciones en función de la coyuntura económica ${ }^{17}$. Dos son las transformaciones que vamos a destacar:

a) Reducción en la duración de los arrendamientos. Los plazos cortos en los contratos de arrendamiento permitían a los propietarios una mejor adecuación de la renta de sus propiedades a las fluctuaciones del mercado lo que posibilitaba el mantenimiento del valor real de la renta e, inclusive, su revalorización en los momentos favorables ${ }^{18}$. A lo largo del

12 Esta modalidad de cesión tenía como punto de partida la parcelación de alguna de las grandes propiedades de la Cartuja, generalmente de mala calidad, para a continuación distribuir los lotes, de 2 a 4 aranzadas de superficie, entre los colonos a cambio del pago de una renta anual perpetua y con la condición de que los colonos roturasen dichas tierras y las pusiesen de viñas.

13 Bernal, A. M., Economía e historia de los latifundios, Madrid, págs. 159-160.

14 Así, en 1730 el duque de Osuna sacó a subasta para su arrendamiento la totalidad de las tierras que constituian su patrimonio rústico y que ascendian a 93.348 fanegas, CONTRERAS, J., "La explotación del patrimonio del duque de Osuna» en ARTOLA, M., El latifundio. Propiedad y explotación, siglos XVII-XX, Madrid, 1978, pág. 70. A su vez, el clero cordobés arrendaba en el siglo Xvil casi el 95\% de sus tierras, MatA OLmo, R., Pequeña y gran propiedad agraria en la depresión del Guadalquivir, Madrid, 1987, J, págs. 248-249.

is Contreras, J., «La explotación del patrimonio...», pág. 66.

16 BERNAL, A. M., La lucha por la tierra en la crisis del Antiguo Régimen, Madrid, 1979, pág. 144.

17 Bernal, A. M., Economía e historia..., pág. 160.

$1 *$ Bernal, A. M., Economía e historia..., pág. 172, ha estimado, a partir de una muestra de más de 100 latifundios, que el incremento de la renta de la tierra en Andalucía Occidental fue a lo largo del siglo Xvir de un $240 \%$.

Hispunia, LVII/2, núm. 196 (1997) 709.729 
período estudiado se va a producir una progresiva reducción de la duración de los contratos de arrendamiento de las propiedades rústicas de los cartujos andaluces tal como se aprecia en el cuadro 3.

CUADRO 3

CONTRATOS DE ARRENDAMIENTO DE LAS PROPIEDADES RÚSTICAS

DE LA CARTUJA DE JEREZ DE LA FRONTERA SEGÚN SU DURACIÓN (siglos xvi-xviI)

\begin{tabular}{ccccccc}
\multicolumn{8}{c}{ Duración (años) } \\
\hline núm. años & 3 & 4 & 5 & 6 & 7 & media \\
\hline $1500-49$ & 2 & - & 5 & 3 & 5 & 5,6 \\
\hline $1550-99$ & 2 & 3 & 5 & 6 & 21 & 6,1 \\
\hline $1600-49$ & 14 & 5 & 13 & 1 & - & 4 \\
\hline $1650-99$ & 56 & 6 & 5 & - & - & 3,2 \\
\hline siglo XVIII $^{19}$ & 24 & 17 & 3 & 4 & & \\
\hline
\end{tabular}

(datos: número de contratos)

Fuente: AHN, Clero, libros 1909, 1912, 1915, 1918, 1929, 1930, 1938, 1939, 2188, 2212 y legajo 1589; AHPC, libros 11 y 12; AHPBF, códices $219,220,221$ y legajo 1 y carpetas $\mathrm{T}$ y $\mathrm{U}$.

b) Sustitución de la renta en especie por renta en metálico. Hasta el siglo XVI predominó el pago de la renta en especie, junto con la cláusula «a esterilidad" en los contratos ${ }^{20}$, aunque después fue imponiéndose el pago en metálico ${ }^{21}$. La sustitución del pago de la renta en especie por el pago de la

GRAFICO 2: RENTA POR UNIDAD DE SUPERFICIE

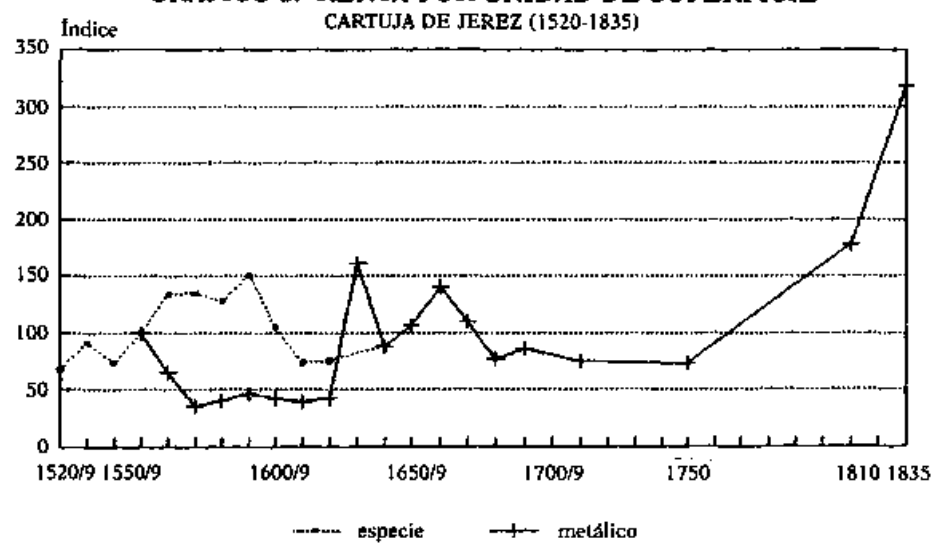

19 Los datos del siglo Xvil no corresponden a la cartuja de Jerez, sino al monasterio de jerónimos de Bornos que tenía 5 cortijos en Jerez en una zona próxima a las de las propiedades de la Cartuja, López MarTinez, A. L., La economía de las órdenes religiosas..,, págs. 318-319.

20 Sobre la modalidad «a esterilidad» en los contratos de arrendamiento vid. MATA OLMo, R., Pequeña y gran propiedad agraria..., vol. I, págs. 252-260.

21 Bernal, A. M., Economía e historia..., pág. 162-163.

Hispatia, LVLi/2, núm. 196 (1997) 709-729 
renta en metálico debió responder a criterios de rentabilidad, como se aprecia cuando se analiza la evolución de la renta de los cortijos y tierras pertenecientes a la Cartuja de Jerez de la Frontera.

Durante el siglo xvI el incremento de la renta en especie por unidad de superficie, unido con el aumento del precio del trigo, determinó una coyuntura favorable para los perceptores de rentas en especie. Esto justifica el hecho de que hasta comienzos del siglo xvi la mayor parte de las rentas de los cortijos arrendados se percibiese en especie. Durante el siglo XvII la caída de la renta en especie, hasta un 50\% en la década 1620-29 y el estancamiento de los precios del trigo ${ }^{22}$, va a dar lugar a una paulatina sustitución por renta en metálico, en la que se aprecia una tendencia alcista durante la primera mitad del siglo xvII. A partir de 1650 no tenemos ningún testimonio de que se pagasen rentas en especie y, por el contrario, todas se pagaron en metálico ${ }^{23}$.

La combinación del arrendamiento a corto plazo y del pago de la renta en metálico reportó una considerable subida de la renta de la tierra a lo largo del siglo XVIII, tanto si lo consideramos en términos absolutos, como si la comparamos con la evolución del precio del trigo. La serie de arrendamientos de los cortijos jerezanos del monasterio de los jerónimos de Bornos nos permite hacer una estimación de tal crecimiento ${ }^{24}$.

El cuadro núm. 4 refleja de modo claro la acertada opción de la combinación antes citada, arrendamientos de corta duración y pago de la renta en dinero, permitían una continua actualización de la renta para adecuarla a las fluctuaciones de la coyuntura. La renta creció siempre por encima del precio del trigo, lo que muestra la elevada rentabilidad de este tipo de arrendamientos. Unicamente, durante las primeras décadas del siglo XIX la evolución se quebró, pero aquí influyeron otros factores ajenos al monasterio y que a medio plazo determinarían la crisis definitiva de las administraciones monásticas.

La renta de los cortijos de los jerónimos aumentó entre 1710-19 y 1790-99 en un $260 \%$, cifra próxima a la estimada por Bernal para una amplia serie de latifundios de Andalucía Occidental, cuya renta creció entre 1700-30 y 178099 en un $240 \%{ }^{25}$

22 Para la evolución de los precios del trigo hemos seguido a Ponsot, P., Atlas de Historia Económica de la Baja Andalucía (Siglos XVI-XIX), Madrid, págs. XXI-XXIll.

${ }^{23}$ Una sustitución similar se produjo en el caso de los cortijos propiedad del convento sevillano de S. Clemente en la primera mitad del siglo XVII, LópEZ MARTiNEZ, A. L., La economía de las órdenes religiosas..., págs. 316-317. Tambien en varios cortijos de la provincia de Cádiz (Jerez de la Frontera, Sanlúcar de Barrameda y Trebujena) el paso de renta en especie a renta en metálico se produjo entre 1580 y 1640 . Sin embargo este cambio no se dió en las provincias del interior, así en Córdoba la cláusula de «a esterilidad» y el pago en especie continuó a lo largo del siglo xvil, Ponsot, P., Atlas de Historia Económica..., págs. 563-664.

${ }^{24}$ Los cinco cortijos jerezanos de los jerónimos de Bornos tenían 4.832 aranzadas, López MARTíNEZ, A. L., La economía de las órdenes religiosas..., pág. 318.

25 Bernal, A. M., «El latifundio y su evolución» en ARTOLA, M., El latifiandio..., pág. 134.

Hispania, LVI:L2, núm. 196 (1997) 709-729 
CUADRO 4

EVOLUCIÓN DE LA RENTA MEDIA ANUAL (por decenios) DE LOS CORTUOS PROPIEDAD DEI, MONASTERIO DE JERÓNTMOS DE BORNOS (1676-1818)

\begin{tabular}{cccccc} 
Años & 1 & 2 & 3 & 4 & $2 / 4$ \\
\hline $1670 / 79$ & 65.306 & 100 & 40 & 100 & 1,0 \\
\hline $1680 / 89$ & 63.150 & 97 & 28 & 70 & 1,4 \\
\hline $1690 / 99$ & 46.515 & 71 & 18 & 45 & 1,6 \\
\hline & & & & & \\
\hline $1710 / 19$ & 41.779 & 64 & 25 & 63 & 1,0 \\
\hline $1720 / 29$ & 42.795 & 66 & 19 & 48 & 1,4 \\
\hline $1730 / 39$ & 48.485 & 74 & 28 & 70 & 1,1 \\
\hline $1740 / 49$ & 46.444 & 71 & 20 & 50 & 1,4 \\
\hline & & & & & \\
\hline $1770 / 79$ & 92.117 & 141 & 40 & 100 & 1,4 \\
\hline $1780 / 89$ & 101.830 & 156 & 45 & 113 & 1,4 \\
\hline $1790 / 99$ & 108.623 & 166 & 44 & 110 & 1,5 \\
\hline $1800 / 09$ & 102.206 & 157 & 74 & 185 & 0,8 \\
\hline $1810 / 19$ & 93.107 & 143 & 77 & 193 & 0,7 \\
\hline
\end{tabular}

base $1670 / 79=100$; datos: 1 y 3 en reales

Claves: $1=$ renta media anual por decenios; $2=$ índice; $3=$ precio medio anual por decenios de la fanega de trigo en Sevilla; $4=$ indice.

Fuentes: 1 y 2, A.L. López Martínez: La de las órdenes religiosas..., págs. 318-319; 3 y 4, P. Ponsot:Atlas de Historia..., pág. 520+521.

\section{EXPLOTACIÓN DIREcta DE LAS PROPIEDADES RÚSTICAS DE LOS CARTUJOS}

Tradicionalmente la gestión directa ha sido considerada como la modalidad más inusual de explotar sus tierras por parte de los grandes propietarios, de los que, como dice Olavide, "...muy pocos se dedican a cultivar sus tierras, reduciéndose casi exclusivamente a la plantación de olivares. Es muy raro que se dediquen a la administración de los cortijos.... ${ }^{26}$. Sin embargo, los mismos ilustrados españoles se lamentaban de que los regulares se dedicasen a cultivar sus tierras ${ }^{27} \mathrm{e}$, incluso, solicitan al monarca que les prohibiese tomar tierras en arrendamiento para su labranza por considerarlo impropio de su oficio ${ }^{28}$.

26 OLAVIDE, Pablo de, Informe acerca de la Ley Agraria, reeditado en LoBo MANZANo, L., «La burguesía ilustrada sevillana ante Ja problemática agrarias: Agricultura y Sociedad, 48 (1988) 379-380.

27 BRUNA, Francisco de, Informe sobre la Ley Agraria, reeditado en LOBO MANZANo, L., "La burguesía ilustrada sevillana...», pág. 142, afirmaba que «...las mayores labores en Andalucia y la mayor copia de ganado está en las comunidades religiosas».

${ }_{28}$ OLAVIDE, P. de, Informe acerca de..., pág. 396, 
Efectivamente, la mayor parte de los grandes propietarios، los nobles, no explotaron sus propiedades directamente o lo hicieron sólo de manera coyuntural, por caída de la renta, por ausencia de arrendatarios... y siempre por corto espacio de tiempo ${ }^{29}$. Sin embargo, otros propietarios, principalmente, algunas comunidades religiosas labraban sus tierras de manera regular y desde el siglo xvI al menos. Esta circunstancia se fue generalizando con el tiempo, siendo en el siglo xviII numerosos los ejemplos disponibles de comunidades labradoras ${ }^{30}$. La extensión de la labranza por parte de las comunidades de regulares alcanzó una amplitud notable en Andalucía, especialmente entre algunas órdenes, cartujos y jesuitas ${ }^{31}$, que cultivaron no solo sus olivares, huertas y viñedos, sino, también, sus cortijos de cereales.

Diferentes factores contribuyeron a esta modalidad de gestión por parte de los regulares, que le dio a sus explotaciones un carácter diferencial respecto a la gestión llevada a cabo por otros grandes propietarios, como la nobleza. Dentro de estos factores pensamos que hay que destacar, especialmente, ciertos incentivos de carácter institucional y organizativo, ciertas prácticas tradicionales de las comunidades eclesiásticas, así como determinados aspectos coyunturales.

Entre los factores institucionales hay que mencionar la exencion, total o parcial, de pagar diezmos por sus propiedades. Dichas exenciones, extensivas a todos los conventos de la misma orden o alguno en concreto, concedidas por Roma fueron concordadas con el cabildo catedralicio hispalense ${ }^{32}$. En el caso de la orden Cartuja la concordia primaba la explotación directa que solo pagaba una parte de cada 50 de cosecha, en el caso de bienes de fundación, frente a las cedidas en arrendamiento, cuyo diezmo se distribuia una parte por cada 30 para la archidiócesis y dos de cada 30 para el monasterio. Esto implicaba que si cultivaban sus tierras sólo pagaban de diezmo al cabildo el $2 \%$ de la cosecha, mientras que si las arrendaban tendrían que pagar como diezmo el 3,33\% de la misma. Además, ello significaba una importante ventaja en el caso de los cartujos frente a los propietarios laicos, ya que mientras que los primeros solo pagarían de diezmo el $2 \%$ de la cosecha, a los segundos les correspondería pagar el $10 \%$.

El segundo factor institucional favorable a las comunidades regulares frente a los propietarios laicos, cara a la gestión directa de sus bienes, lo constitufan los privilegios fiscales que gozaban los eclesiásticos en la comerciali-

29 AMALRIC, J. y PONSOT, P., L'exploitation des grands domaines dans l'Espagne d'Ancien Regime, Paris, 1985, págs. 5-6, afirman que la explotación directa de los latifundios tuvo un carácter excepcional, determinado, sobre todo, por la coyuntura, por lo que hay que considerarla como una solución de reemplazo a corto plazo del arrendamiento.

30 Donínguez OrTiz, a., «Campomanes y los monjes-granjeros. Un aspecto de la política eclesiástica de la llustración», Cuadernos de Investigación Histórica, 1 (1977) 99-109, ha estudiado el caso de estos monjes-granjeros, que sufrieron las diatribas de los ilustrados, especialmente de Campornanes.

31 La explotación del cortijo Espartinas por los jesuitas en LÓPEZ MARTiNeZ, A. L., La economia de las órdenes religiosas..., págs. 290-303.

32 La mayor parte de las concordias diezmales están contenidas en el Libro de Concordias de Diezmos, ACS, Justicia, 103.

Hispania, LVII/2, nủm. 196 (1997) 709-729 
zación de sus cosechas. El título IX del libro I de la Novísima Recopilación de las Leyes de España, contempla las exenciones fiscales de los eclesiásti$\cos$. Las leyes que más concretamente mencionan los privilegios de los eclesiásticos son la VI, referida a la exención de pechos y tributos de los clérigos, las leyes VIII, IX y X sobre que los clérigos no paguen alcabalas de las ventas que efectúen de sus bienes y, por último, la ley XII sobre que no se les cobre alcabalas a los clérigos de Jerez de la Frontera por la venta de los frutos de sus propiedades «...de las tierras de pan llevar, huertos, frutos y olivares». Estos privilegios favorecían la comercialización de la producción agraria de los regulares, lo que permitía redondear los beneficios de su explotación ${ }^{33}$.

En tercer lugar, los regulares usaron de su condición de vecinos en aquellas tierras en las que tenían propiedades con el fin de utilizar libremente las dehesas comunales. Esta práctica, aunque irregular, debía estar muy generalizada, como afirma F. Bruna cuando dice que los ganados de los monasterios inundan los campos. Del mismo modo se manifiesta la ley IX del libro VII, título XXVI de la Novísima Recopilación que denuncia el abuso que gozan los eclesiásticos del derecho de vecindad en los pueblos donde no están situados y que limita dichos derechos a los pueblos donde radican dichas comunidades y no a donde están situadas sus propiedades.

Por último, consideramos que otra ventaja de las comunidades de regulares la constituyó el propio capital humano disponible, dado el número de los religiosos que componían las comunidades y su preparación tanto intelectual, como en las tareas de gestión administrativa y, en concreto, en las explotaciones agrarias ${ }^{34}$. A este respecto conviene destacar la propia organización administrativa de los cartujos que permitía una gestión jerarquizada y fuertemente controlada, lo que redundaba en una mayor eficacia de la misma.

Al frente de todas las explotaciones se encontraría el Procurador Mayor, a las órdenes inmediatas del Abad del monasterio. Bajo el control del Procurador Mayor, se encontraban las diferentes secciones que constituían la administración central del monasterio: procuraduría, arca, casa de la carne, horno, ganado, herrería... Estas secciones recibían los productos enviados por las diferentes granjas y atendían, a su vez, sus demandas tanto en metálico, como en especie.

Los hermanos administradores eran los encargados de la gestión de cada una de las propiedades explotadas directamente. El procurador suministra el dinero necesario para la labor de cada explotación, salarios, jornales y adquisición de suministros. La autonomía de los administradores de las fincas es reducida, ya que ha de remitir la mayor parte de la producción de la finca al

33 BRUNA, F. de, Informe sobre..., pág. 442, afirma que los regulares podian vender sus frutos a precios más cómodos por sus franquezas.

34 Son numerosos los ejemplos de tratados de agronomía escritos por religiosos, destacando a este respecto los efectuados por los jesuitas para los hermanos administradores de sus haciendas, LOPEZ Martinez, A. L., "Las explotaciones agrarias de los jesuitas en Andalucía Occidental» en TORRES Ramirez, B. (ed.), Propiedad de la tierra, latifundios y movimientos campesinos, Sevilla, 1991, pág. 210. Para Andalucia contamos, entre otras, con las ordenanzas para la administración de sus propiedades elaboradas por los jerónimos de S. Isidoro del Campo en Santiponce, en las afueras de Sevilla, conservadas en la Bibljoteca Universitaria de Sevilla y estudjadas por A. Dominguez Ortiz (1977b). 
monasterio, donde se destina al consumo de la comunidad, se pagan diezmos e impuestos y se comercializa el excedente. También existe una relación entre cada granja del monasterio y las restantes sin pasar por el Procurador Mayor ${ }^{35}$. La administración está configurada de modo que las relaciones con el exterior son mínimas, por lo que se puede hablar de una economía casi cerrada en lo que se refiere a la adquisición de suministros para las explotaciones, pero no así en lo que respecta a la venta de sus excedentes que se comercializaban en las grandes ciudades próximas de Cádiz, Jerez de la Frontera y Sevilla.

De la centralización de la administración económica de la cartuja nos da idea la distribución de la producción del cortijo Gambogaz, propiedad de la Cartuja de Sevilla:

$\begin{array}{lr}\text { - Enviada al convento } & 72 \% \\ \text { - Vendida en el cortijo } & 23 \% \\ \text { - Enviada a otras granjas } & 5 \%\end{array}$

Junto a estos factores que hemos denominado institucionales hay que mencionar uno de carácter coyuntural, nos referimos a la evolución media de los salarios en relación con el índice de precios al consumo. El índice de salarios, es un índice ponderado de las cantidades pagadas cada año por el cortijo en concepto de salarios a los trabajadores fijos y jornales a los empleados en las faenas de cereal, olivar, viña y hornos ${ }^{36}$, de todo ello resulta lo reflejado en el cuadro 5.

CUADRO 5

EVOLUCIÓN DE LOS SALARIOS PAGADOS EN EL CORTIJO DE GAMBOGAZ (1704-1740)

\begin{tabular}{cccc} 
años & salarios & precios & salarios reales \\
\hline $1704 / 09$ & 94,9 & 104,4 & 90,9 \\
\hline $1710 / 19$ & 102,5 & 102,3 & 100,2 \\
\hline $1720 / 29$ & 102,0 & 94,6 & 107,8 \\
\hline $1730 / 39$ & 92,1 & 100,3 & 91,8 \\
\hline $1704 / 39$ & 98,1 & 100,0 & 98,1 \\
\hline
\end{tabular}

base $1704 / 39=100,0$

datos: indices de salarios elaborados a partir del cuaderno de contabilidad del cortijo Gambogaz, APBF, códice 203; el indice de precios ha sido elaborado a partir de los datos de P. Ponsot 1986, utilizando los factores de ponderación del trigo, cebada, aceite y vino calculados por P. Martín Aceña ${ }^{37}$

35 López Martinez, A. L., «El patrimonio económico de la Cartuja de Santa Maria de las Cuevas de Sevillas: Historia de la Cartuja de Sevilla. De ribera del Guadalquivir a recinto de la Exposición Universal, Madrid, 1989, págs. 221-222.

36 Sobre los salarios del cortijo Gambogaz en la primera mitad del siglo xvin estamos efectuando un estudio a partir de su cuaderno de cuentas (APBF, cód. 203), en que se incluyen abundantes datos de los mismos. Esta explotación empleaba 10 ó 12 trabajadores fijos y daba más de 15.000 jornales a trabajadores eventuales.

37 «Los precios en Europa en los siglos xvi y xvil», Revista de Historia Económica, 1992, X, núm. 3, pág. 362.

Hispania, LV!I/2, nưm. 196 (1997) 709-729 
Los datos anteriores reflejan una subida de los precios ligeramente superior a la de los salarios, lo que beneficiaría a los empleadores de mano de obra. Aunque los datos para comparar no son muchos, la misma evolución ha sido señalada por Ponsot cuando afirma que los salarios de los trabajadores agrícolas experimentaron una ligera tendencia decreciente hasta mediados del siglo xviI ${ }^{38}$. En estas circunstancias no es de extrañar que la explotación directa de las tierras de las cartujas andaluzas fuese en continua progresión, tal como aparece indicado en el cuadro 6.

\section{CUADRO 6}

APROVECHAMIENTOS EN LAS TIERRAS EXPLOTADAS DIRECTAMENTE POR LA CARTUJA DE JEREZ DE LA FRONTERA (1513-1835)

\begin{tabular}{cccccc} 
Años & Cereal & Pastos & Olivar & Viña & Otros \\
\hline 1513 & & 113 & 85 & 72 & \\
\hline 1578 & 1.945 & 720 & & & \\
\hline 1651 & 2.988 & 420 & 290 & & \\
\hline 1717 & 2.400 & 1.950 & 300 & 84 & 18 \\
\hline 1750 & 3.553 & 440 & 1.387 & 108 & 23 \\
\hline 1810 & 4.085 & 1.820 & 1.395 & 100 & \\
\hline 1820 & 173 & & 1.415 & 113 & \\
\hline 1835 & & & 109 & 5 & \\
\hline
\end{tabular}

superficie: aranzadas

Fuente: las del cuadro núm. 2

Hay que destacar el importante incremento experimentado por las tierras cultivadas por la comunidad, especialmente, desde mediados del siglo xVII y a todo lo largo del siglo XVIII, hasta constituir el $80 \%$ de todo el patrimonio rústico monástico. Pero, sobre todo, lo más significativo, por su singularidad es la explotación directa de las tierras de cereal, cuya superficie se duplicó desde finales del siglo xvi, hasta alcanzar el $50 \%$ de las tierras monásticas.

\section{EXPANSIÓN DEL CULTIVO DEL OLTVAR}

A lo largo del siglo xvII, especialmente en su segunda mitad, se produjo un importante crecimiento de la superficie dedicada al olivar en Andalucía, afectando practicamente a la totalidad de sus regiones ${ }^{39}$. En este desarrollo del cultivo del olivar jugarian un papel muy importante las explotaciones agrarias

38 Ponsot, P., Atlas de Historia Económica..., pág. XXVI.

39 Zambrana Pineda, J. F., Crisis y modernización del olivar español. 1870-1930, Madrid, 1987, pág. 53 (nota 1), afirma que la importante expansión de este cultivo alcanzada durante las décadas centrales del siglo $\mathrm{xIX}$ fue el tramo final de un movimiento que se inició an siglo antes. 
de las órdenes religiosas en el reino de Sevilla ${ }^{40}$, que ya a mediados de siglo dedicaban a este cultivo más de 14.000 has., que equivalían al $13 \%$ de su patrimonio rústico ${ }^{41}$. En este proceso de incremento de la superficie dedicada al olivar ${ }^{42}$ van a destacar las cartujas andaluzas (cuadro 7).

CUADRO 7

EVOLUCIÓN DE LA SUPERFICIE DEDICADA A OUTVAR POR LAS CARTUJAS ANDALUZAS. (siglo xvisi)

\begin{tabular}{cccc} 
& 1717 & 1752 & 1824 \\
\hline Sevilla & 351 & 455 & 739 \\
\hline Jerez & 300 & 1.387 & 1.415 \\
\hline Cazalla & 408 & 540 & \\
\hline
\end{tabular}

(datos en aranzadas)

Fuente: ACS, Mesa Capitular, 1.165b, para 1717; ACS, Mesa Capitular, 1.174 (94), para 1752; APBF, Legajo 1, para Sevilla en 1824 y códice 178, para Jerez de la Frontera

La evolución de la superficie dedicada al olivar puede ser justificada por la comparación de los precios del trigo y del olivar en el mercado sevillano (ver gráfico 3). Del estudio de los mismos se desprende que tanto los precios del

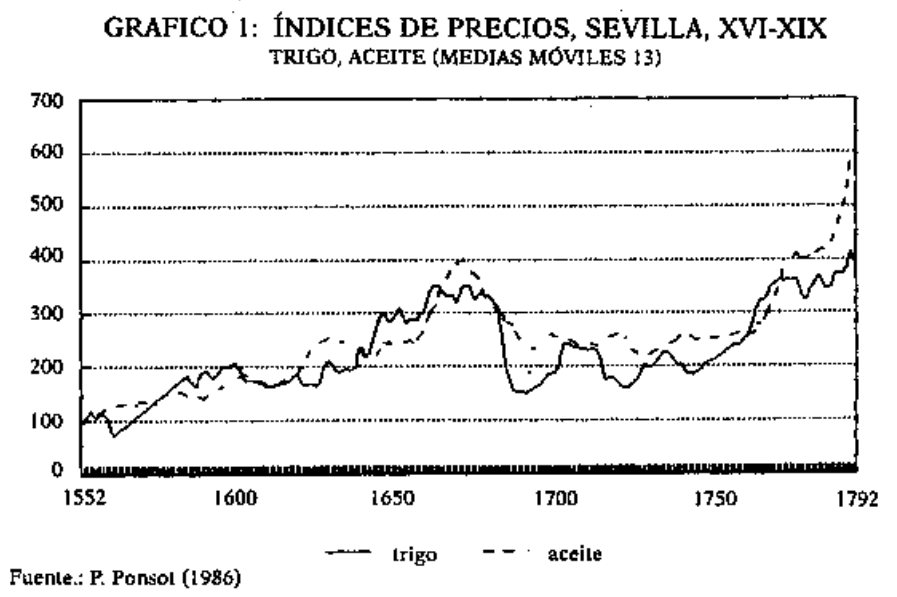

40 El convento de Sta. Inés de Ecija es un ejemplo de dicha evolución, en 1717 tenía 66 aranzadas dedicadas al olivar, que pasan a ser 235 en 1752, para llegar a las 523 en 1796, LÓPEZ MARTíNEZ, A. L., «Crisis y reconversión de las economías monásticas en la crisis del Antiguo Régimen. El monasterio de Santa Inés de Écija en el siglo XIX»: Archivo Hispalense, 230 (1992) 8-11.

41 López Martínez, A. L., La economía de las órdenes religiosas..., pág. 63.

42 Bernal, A. M., Economia e historia..., pág. afirma que el cultivo del olivar es la más rentable de las explotaciones agrarias, debido a que une la producción con la comercialización.

Hisponia, LVII/2, nutm. 196 (1997) 709-729 
aceite como los del trigo experimentaron una fuerte caída a partir de la década de los 70 del siglo xviI, estancándose posteriormente a un bajo nivel hasta la década de los 60 del siglo xviII. La caída y el posterior estancamiento fue mayor en el caso del trigo, cuyo precio se mantuvo un $27 \%$ por debajo de los del aceite a partir de 1670. Desde esta fecha y hasta finales del siglo xvin los índices de precios del aceite fueron casi siempre por encima de los del trigo.

\section{RENTARIIDAD DE LA EXPLOTACIÓN DIRECTA. LAS CUENTAS DEL CORTUO DE GAMBOGAZ.}

El cortijo de Gambogaz estaba situado en la orilla derecha del Guadalquivir, constituido por tierras de excelente calidad, muy próximo a la ciudad de Sevilla y al mismo monasterio, lo que determinaba una elevada renta de situación y facilitaba su explotación directa. El cortijo estaba ya adquirido desde finales del siglo XV ${ }^{43}$, no experimentando variaciones sustanciales en su superficie:

- 1715: 693 aranzadas de sembradura +219 aranzadas de olivar ${ }^{44}$

- 1750: 560 fanegas de sembradura +290 fanegas de olivar ${ }^{45}$

- 1824: 584 aranzadas de tierra calma +214 aranzadas de olivar ${ }^{46}$

Además había una superficie reducida de viña, entre 10 y 20 aranzadas, que iba en claro retroceso, en el prontuario de 1824 sólo se citan 6 aranzadas. El olivar, con molino de aceite propio, se explotaba, al menos, desde comienzos del siglo XVI, como lo testimonian los contratos con cuadrillas de jornaleros para coger la aceituna que se encuentran en el Archivo de Protocolos de Sevilla. No sabemos cuando comienza la explotación directa de la tierra calma, aunque, por lo dicho anteriormente, debió de ser, también, en fecha bastante temprana. La explotación directa por parte de la Cartuja se mantuvo hasta la Guerra de la Independencia, tras la cual aunque se intentó reanudar la explotación directa, los muchos daños causados por la guerra hicieron fracasar dicho proyecto y tener que recurrir al arrendamiento de sus tierras ${ }^{47}$.

43 Lopez MARTineZ, A. L., La economia de las órdenes religiosas..,, págs. 217-218.

44 ACS, Mesa Capitular, libro 1.165b.

4 ACS, Mesa Capitular, libro 1.174.(94).

46 APBF, leg. 1.

47 El monasterio, tras la exclaustración de los monjes, sirvió de cuartel general a las tropas francesas de ocupación. A la vuelta, los cartujos tuvieron que hacer frente a los muchos destrozos ocasionados lo que les llevó a endeudarse. La pétdida de buena parte del ganado de labor y aperos y las malas , cosechas, impidieron la reanudación plena de la explotación de Gambogaz, por lo que los monjes se vieron obligados a desistir, artendar el cortijo y vender ganado y enseres para pagar sus deudas. AHPSE, Protocolos Notariales, leg. 2938: f. 147, obligación de 200.000 reales de la Cartuja de Sevilla con T. Gutiérrez; f. 513, arrendamiento del cortijo Gambogaz a T. Gutiérrez; f. 545, venta de la cosecha de arigo y cebada de Gambogaz a L. Romero con quien la Cartuja tenía una deuda de más de 50.000 reales, resto de mayor cantidad; f. 549, venta del ganado de labor y enșeres de Gambogaz a T. Gutiérrez. 
El cuaderno de cuentas de 1704 a 1740 contiene la rendición de cuentas por parte del hermano administrador al Procurador Mayor del monasterio de la distribución del dinero enviado por este para atender los gastos de explotación del citado cortijo, que se cultivaba según el sistema de "año y vez", sembrándose en la hoja de cultivo trigo, cebada y semillas (garbanzos, alberjones, yeros, etc.). Aparece una detallada relación de los gastos salariales, así como de la distribución de la producción de la finca entre lo que se enviaba al convento y a otras granjas de este y lo que se vendía en el cortijo. También se detallan todas las especies que el cortijo recibía de las diferentes secciones y granjas del monasterio. Todo ello permite analizar como funcionaba esta explotación, así como aproximamos a cual sería el comportamiento de la economía monástica en su conjunto. Sin embargo, faltan algunos datos muy importantes para reconstruir lo que serfa la evolución de la contabilidad de la explotación agraria, en concreto la parte dedicada al autoabastecimiento, o sea, semillas para cereales y alimentación de los trabajadores empleados en la granja y el ganado de labor de la misma.

Al final de cada año se ofrece, a modo de balance, un estado de los ingresos y gastos que ha tenido el administrador, valorando a precio de mercado las especies que se han enviado al monasterio y a las granjas, así como lo que de ellos se ha recibido, lo que permite la estimación de la utilidad que ha tenido la explotación.

\section{Ingresos del cortijo Gambogaz}

El cortijo de Gambogaz comprende una compleja estructura en la que se integran la tierra calma dedicada a la sembradura de cereal (trigo, cebada y semillas), el olivar, un viñedo, dos hornos, uno de ladrillo y otro alfarero y una carpintería además de algunos talleres donde se elaboraban y reparaban algunos aperos de labranza. La producción de esta explotación está compuesta por trigo, cebada, semillas y paja procedentes de la tierra calma, aceite, aceitunas, orujo y leña del olivar, vino y vinagre del viñedo, ladrillos, cangilones y piezas de alfarería de los hornos y diferentes repuestos de madera, reparaciones de aperos y carretas del monasterio.

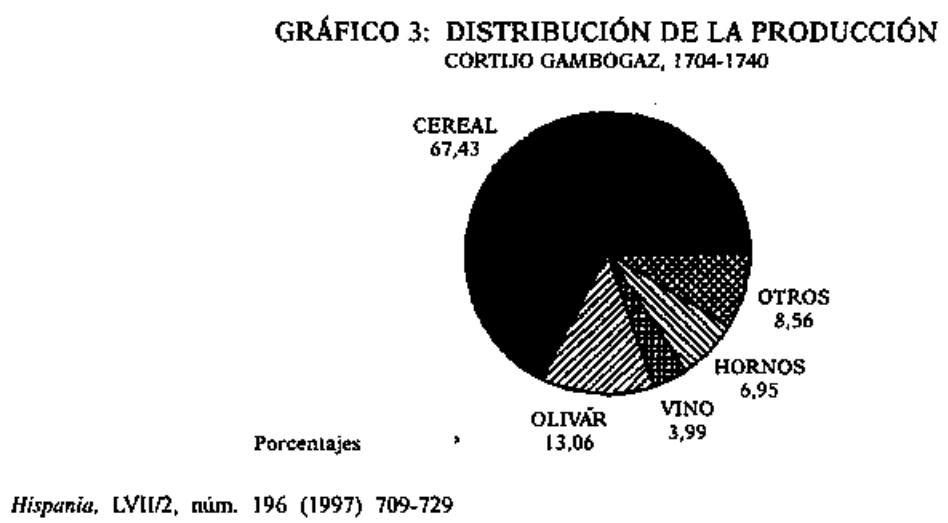


A pesar de las deficiencias de la documentación utilizada podemos intentar aproximarnos lo más posible a la producción final del cortijo Gambogaz, para lo cual nos valdremos de otras estimaciones efectuadas para otras explotaciones. El dato del que vamos a partir es el del valor de los productos enviados al convento y a las granjas y el comercializado directamente por el cortijo, que en total asciende a 4.248.273 reales. Dicho producto debe ser incrementado con el gasto efectuado en semilla, en el caso de los cereales, más el producto del diezmo, que no era pagado por el cortijo, sino por el monasterio para todo el conjunto de sus propiedades. Algunas estimaciones efectuadas para otras explotaciones ${ }^{48}$ y dada la calidad de las tierras cultivadas, nos lleva a considerar un rendimiento de 6 unidades cosechadas por cada 1 de semilla. Por otra parte, de acuerdo con la concordia efectuada con el Cabildo de la Catedral sevillana, la Cartuja pagaría 1 parte de cada 50 cosechadá en las tierras de fundación explotadas directamente, caso del cortijo Gambogaz, lo que supone un $2 \%$ de la cosecha. Partiendo de la distribución por aprovechamientos del producto del cortijo resultaría

\section{CUADRO 8}

ESTIMACIÓN DEL VALOR DE La PRODUCción TOTAL DEL CORTWO GAMBOGAZ (1704-1740)

\begin{tabular}{ccccc} 
Productos & 1 & 2 & 3 & Total \\
\hline Cereal & 2.678 .536 & 535.707 & 64.285 & 3.278 .528 \\
\hline Olivar & 622.797 & & 12.456 & 635.253 \\
\hline Viña & 190.323 & & 3.806 & 194.129 \\
\hline Hornos & 338.163 & & & 338.163 \\
\hline Otros & 416.330 & & & 416.330 \\
\hline Total & 4.248 .273 & 535.707 & 80.547 & 4.862 .403 \\
\hline
\end{tabular}

claves: 1 = producto comercializado y enviado al monasterio y granjas; $2=$ semillas; $3=$ diezmo datos: reales

Fuente: Libro de cuentas del cortijo Gambogaz, APBF, códice 203.

\section{Gastos de la explotación}

Con los datos disponibles resulta difícil elaborar una contabilidad agraria con criterios modernos, que tenga en cuenta el coste de los diferentes factores productivos, pero se puede intentar efectuar una aproximación a la misma. El factor trabajo presenta ciertas dificultades para su calculo, pues aunque no tenemos ninguna dificultad para conocer los pagos efectuados en metálico, salarios y jornales, sin embargo las fuentes no son explícitas con

48 Ver, sobre todo Ponsot, P., Atlas de Historia Económica..., págs. 471-497 y López MarTíNEZ, A. L., La economía de las órdenes religiosas..., págs. 296. 
las retribuciones en especie. Por ello desistimos de proceder a calcular los ingresos efectivos de los diferentes grupos de trabajadores que están empleados en el cortijo, aunque sí conocemos sin dificultad el volumen de sus ingresos en metálico. El volumen total de la parte de los salarios pagada en especie equivaldría a la suma de los víveres enviados al cortijo por el monasterio y las otras granjas, más las compradas por el propio cortijo directamente. La retribución en especie la hemos repartido entre los diferentes aprovechamientos agrícolas según los porcentajes establecidos para la producción.

El mayor problema que se nos plantea es el del valor del factor tierra, ya que la documentación utilizada no ofrece ninguna aproximación a dicha estimación. Sin embargo, a partir de otras explotaciones es posible intentar cuantificar este valor. Lo primero que hay que tener en cuenta es que para calcular el valor del factor tierra no nos interesa el precio de venta de la misma sino su renta, ya que la venta de las propiedades amortizadas, inalienables según la legislación, no era la alternativa a la producción, sino el arrendamiento. Existen numerosas series de arrendamientos de tierras de cereal para Andalucía Occidental, que nos pueden servir como referencia a la hora de calcular la renta de Gambogaz:

- 6 cortijos Utrera ${ }^{49}$, renta media $1700-40,4,5$ reales/fanega

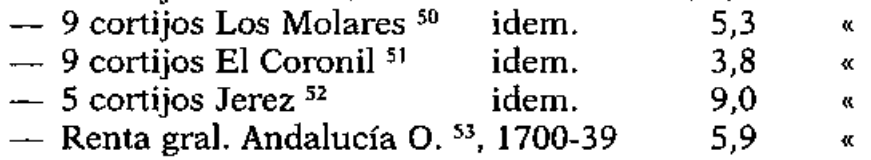

La calidad de la tierra del cortijo Gambogaz, unido a su elevada renta de situación, inmediato a la ciudad de Sevilla, nos hace que le otorguemos al cortijo una elevada renta, que podemos considerar en torno a los 9 reales/ fanega, igual al máximo de los valores anteriores. Las 600 fanegas que componen el cortijo suponen una renta de 5.400 reales anuales.

En el caso del olivar y el viñedo la alternativa no es la de explotación directa o arrendamiento, sino la de estos aprovechamientos o su arrendamiento como tierra de cereal, ya que este tipo de cultivos no solían arrendarse, sino que se cultivaban por sus propietarios. Estimando la misma renta que en el caso del cereal las 250 fanegas, superficie media, destinadas a olivar supondrían una renta de 2.250 reales anuales y en el caso del viñedo las 15 fanegas proporcionarian 135 reales anuales. Lo que supondría una renta anual para toda la finca de 7.785 reales.

\footnotetext{
49 Ponsor, P., Atlas de Historia Económica..., pág. 661.

50 PONSOT, P., Atlas de Historia Económica..., pág. 631 .

51 Ponsot, P., Atlas de Historia Económica..., pág. 609.

52 Lópz MarTineZ, A. L., La economía de las órdenes religiosas,.., págs. 318-319.

53 BERNAl, A. M., Economia e historia..., pág. 172. 
CUADRO 9

COSTES DE PRODUCCIÓN DEL CORTJO GAMBOGAZ, 1704-1740

\begin{tabular}{cccccccc} 
& 1 & 2 & 3 & 4 & 5 & 6 & Total \\
\hline Cereal & 685.853 & 672.605 & 12.479 & 535.707 & 64.285 & 199.800 & 2.170 .729 \\
\hline Olivar & 157.270 & 156.390 & 2.902 & & 12.456 & 83.250 & 412.268 \\
\hline Viña & 59.153 & 47.792 & 887 & & 3.806 & 4.995 & 116.633 \\
\hline Hornos & 78.158 & & & & & & 78.158 \\
\hline Otros & 58.911 & & & & & & 58.911 \\
\hline Total & $\mathbf{1 . 0 3 9 . 3 4 5}$ & $\mathbf{8 7 6 . 7 8 7}$ & 16.268 & 535.707 & $\mathbf{8 0 . 5 4 7}$ & 288.045 & 2.836 .699 \\
\hline
\end{tabular}

datos en reales

claves: 1 = jornales y salarios; 2 = parte proporcional de alimentos procedentes del monasterio y granjas; 3 = parte proporcional de alimentos comprados por el cortijo; $4=$ semilla; $5=$ diezmo; $6=$ renta de la tierra estimada.

Fuente: APBF, cód. 203

\section{Utilidad de la explotación del cortijo Gambogaz}

La comparación de los ingresos y costes de explotación de la granja Gambogaz permite conocer cuales fueron los resultados de dicha explotación

CUADRO 10

UTILIDAD Y RENDIMIENTOS DEI. CAPITAL DEL CORTJO GAMBOGAZ, 1704-40

\begin{tabular}{ccccc} 
Aprovechamiento & Producto & Gastos & Utilidad & Util/Gastos \\
\hline Cereal & 3.278 .528 & 2.170 .729 & 1.107 .799 & $51,03 \%$ \\
\hline Olivar & 635.253 & 412.268 & 222.985 & $54,09 \%$ \\
\hline Viña & 194.129 & 116.633 & 77.496 & $66,44 \%$ \\
\hline Hornos & 338.163 & 78.158 & 260.000 & $332,67 \%$ \\
\hline Otros & 416.330 & 58.911 & 357.419 & $606,71 \%$ \\
\hline Total & 4.862 .403 & 2.836 .699 & 2.025 .704 & $71,41 \%$ \\
\hline
\end{tabular}

datos en reales

Fuente: APBF, cod. 203

La simple comparación de las utilidades producidas por la explotación de Gambogaz, 2.025.704 reales, que equivalen a 54.749 reales anuales, en relación con la otra alternativa, que era la del arrendamiento como tierra de cereal, 288.045 reales, o sea 7.785 reales anuales, evidencia claramente el beneficio que reportó la explotación directa. La proporción de los ingresos de la explotación directa sobre el arrendamiento fue de 7 a 1 . Esto se debe no sólo a la diferencia entre explotación directa y arrendamiento, sino también a las posibilidades que ofrecía la primera de acometer una explotación inte- 
gral de los recursos disponibles, mediante una explotación agropecuaria y artesanal ${ }^{54}$.

Indiscutiblemente el exito de las transformaciones acaecidas en las administraciones del patrimonio cartujo debió traducirse en un considerable incremento de los ingresos monásticos. Lamentablemente no hemos podido localizar la contabilidad general de ninguno de los dos monasterios por lo que es imposible estimar en cuanto se incrementaron dichos ingresos, pero hay indicadores que nos pueden dar una idea de ello. Uno de los principales beneficiarios de este incremento de los ingresos monásticos sería sin duda alguna el capítulo de bienes suntuarios, lo que concuerda con el hecho de que a lo largo del siglo xvIII el monasterio sevillano de Las Cuevas experimentó un trascental proceso de renovación artística ${ }^{55}$.

Más indicativo del éxito alcanzado por las medidas económicas mencionadas resulta la evolución de los gastos totales de la cartuja jerezana que aunque con algunas lagunas hemos logrado reconstruir desde 1596 hasta 1787 (cuadro 12) y que refleja la siguiente evolución:

CUADRO 12

EVOLUCIÓN DE LOS GASTOS DE LA CARTUJA DE JEREZ DE LA FRONTERA (1595-1787)

\begin{tabular}{cccc} 
Años & 1 & 2 & 3 \\
\hline $1596-1600$ & 112.307 & 100,00 & \\
\hline $1606-1609$ & 128.725 & 114,62 & \\
\hline $1649-1656$ & 359.355 & 319,98 & $\mathrm{r}_{(1596-1649)}=2,32 \%$ \\
\hline $1726-1730$ & 387.441 & 344,98 & $\mathrm{r}_{(1649-1730)}=0,02 \%$ \\
\hline 1764 & 489.173 & 435,57 & $\mathrm{r}_{(1730-1764)}=0,71 \%$ \\
\hline $1785-1787$ & 513.961 & 457,64 & $\mathrm{r}_{(1764-1787)}=0,07 \%$ \\
\hline
\end{tabular}

datos: reales

Claves: $1=$ gasto medio mensual; $2=$ fndice; $3=$ tasa de crecimiento anual

Fuentes: AHN, Clero, libro 1.923; AHN, Clero, libro, 1927; AHN, Clero, libro 1.922; APBF, códice 311; AAS Certificaciones de ingresos y gastos; AHN, Clero, libro 1.926.

De todo lo anteriormente expuesto nada parece indicar a finales del siglo XVIII que la situación económica de los monasterios andaluces preludiase su próximo final. Aunque con las oscilaciones propias de una economía del Anti-

$\$ 4$ El cortijo de Gambogaz estaba situado sobre tierras arcillosas de gran calidad que servian a los alfareros trianeros para su abastecimiento de barro, lo que llevó a los cartujos a levantar dos hornos en el cortijo, uno de ladrillos y otro de canales y vasijas. Buena parte de la producción de estos hornos se empleaba para reparaciones de edificaciones propiedad de la Cartuja, el resto se vendia.

35 Morales, A. J., «El patrimonio artistico de la Cartuja de Sevilla»: Historia de la Cartuja de Sevilla..., pág. 174 .

Mispania, LVII/2, núm. 196 (1997) 709-729 
guo Régimen, la tendencia de los gastos del cenobio, utilizados como indicador de sus ingresos, se muestra claramente positiva. Por todo ello, nos ratificamos en lo que ya hemos expuesto en anteriores ocasiones, que la crisis de las economías monásticas andaluzas al final del Antiguo Régimen no obedeció a causas endógenas, intrínsecas a la propia administración monástica, sino que respondió claramente de la actuación de los agentes externos de caracter bélico y político-fiscal que imposibilitaron proseguir el tipo de administración de sus dominios, con un destacado papel de la explotación directa, que se había ido gestando, posiblemente, desde el siglo XvI.

Hispania, LVII/2, núm. 196 (1997) 709-729 